\title{
Age-associated variation in the expression and function of TMEM16A calcium-activated chloride channels in the cochlear stria vascularis of guinea pigs
}

\author{
YING ZHOU $^{1,2^{*}}$, JIA SONG $^{1,3^{*}}$, YAN-PING WANG ${ }^{1,4,5^{*}}$, AI-MEI ZHANG ${ }^{1,6}$, CHAO-YANG TAN $^{1,2}$, \\ YAN-HUI LIU ${ }^{1,7}$, ZHI-PING ZHANG ${ }^{1,6}$, YANG WANG ${ }^{1,2}$, KE-TAO MA ${ }^{1,2}$, LI LI ${ }^{1,2,4}$ and JUN-QIANG SI ${ }^{1,2,8,9}$ \\ ${ }^{1}$ Department of Physiology, Medical College of Shihezi University; ${ }^{2}$ Key Laboratory of Xinjiang Endemic and Ethnic Diseases, \\ Medical College of Shihezi University, Shihezi, Xinjiang 832002; ${ }^{3}$ Department of Stomatology, Medical College of Zhaoqing, \\ Zhaoqing, Guangdong 526000; ${ }^{4}$ Department of Physiology, Medical School of Jiaxing College, Jiaxing, Zhejiang 314000 ; \\ ${ }^{5}$ Nursing Department, Medical School of Jiaxing University, Jiaxing, Zheijang 314001; ${ }^{6}$ First Affiliated Hospital \\ of The Medical College, Shihezi University, Shihezi, Xinjiang 832002; 7 Cardiovascular Medicine Department, \\ Aici District Hospital of Langfang, Langfang, Hebei 065000; ${ }^{8}$ Department of Neurobiology, Tongji Medical College, \\ Huazhong University of Science and Technology; ${ }^{9}$ Department of Physiology, Wuhan University \\ School of Basic Medical Sciences, Wuhan, Hubei 430000, P.R. China
}

Received October 11, 2018; Accepted May 20, 2019

DOI: $10.3892 / \mathrm{mmr} .2019 .10423$

\begin{abstract}
The present study was designed to investigate the expression and function of transmembrane protein 16 (TMEM16A), a calcium-activated chloride channel (CaCC), in the stria vascularis (SV) of the cochlea of guinea pigs at different ages, and to understand the role of $\mathrm{CaCCs}$ in the pathogenesis of presbycusis (age-related hearing loss), the most common type of sensorineural hearing loss that occurs with natural aging. Guinea pigs were divided into the following groups: 2 weeks (young group), 3 months (youth group), 1 year (adult group), D-galactose intervention (D-gal group; aging model induced by subcutaneous injection of D-galactose) and T16Ainh-A01 (intraperitoneal injection of $50 \mu \mathrm{g} / \mathrm{kg} /$ day TMEM16A inhibitor T16Ainh-A01 for 2 weeks). Differences in the hearing of guinea pigs between the various age groups were analyzed using auditory brainstem response
\end{abstract}

Correspondence to: Professor Jun-Qiang Si, Department of Physiology, Medical College of Shihezi University, Building 1, 192 Beier Road, Shihezi, Xinjiang 832002, P.R. China

E-mail: sijunqiang@shzu.edu.cn

Professor Li Li, Department of Physiology, Medical School of Jiaxing College, 118 Jiahang Road, Jiaxing, Zhejiang 314000, P.R. China

E-mail: 1ily7588@163.com

*Contributed equally

Key words: age-associated deafness, stria vascularis, calciumactivated chloride channels, transmembrane protein 16 , presbycusis, endocochlear potential
(ABR), and immunofluorescence staining was performed to detect TMEM16A expression in the SV and determine the distribution. Reverse transcription-quantitative PCR and western blot analyses were conducted to detect the mRNA and protein levels of TMEM16A in SV in the different age groups. Morris water maze behavior analysis demonstrated that spatial learning ability and memory were damaged in the D-gal group. Superoxide dismutase activity and malondialdehyde content assays indicated that there was oxidative stress damage in the D-gal group. The ABR thresholds gradually increased with age, and the increase in the T16Ainh-A01 group was pronounced. Immunofluorescence analysis in the cochlear SV of guinea pigs in different groups revealed that expression of TMEM16A increased with increasing age (2 weeks to 1 year); fluorescence intensity was reduced in the D-gal model of aging. As the guinea pigs continued to mature, the protein and mRNA contents of TMEM16A in the cochlea SV increased gradually, but were decreased in the D-gal group. The findings indicated that $\mathrm{CaCCs}$ in the cochlear SV of guinea pigs were associated with the development of hearing in guinea pigs, and that downregulation of TMEM16A may be associated with age-associated hearing loss.

\section{Introduction}

Age-related hearing loss (AHL), also termed presbycusis, is the pathological and physiological phenomenon by which hearing gradually declines, and can even be lost completely, with gradual aging (1). The elderly ( $>65$ years old) account for $\sim 10 \%$ of the global population, and this number is increasing. As the aging population increases, the number of cases of deafness is predicted to increase. When patients cannot hear clearly, their ability to communicate with others is impaired, and participation in social activities may decline, 
which in turn can affect quality of life $(2,3)$. Thus, deafness is considered a major hidden danger to social stability. AHL is classified into five types: Acoustic presbycusis, neurological presbycusis, stria vascularis (SV) presbycusis (also termed metabolic presbycusis), cochlear conductivity presbycusis and mixed presbycusis (4). Among these types, metabolic presbycusis is the most common (4). Metabolic presbycusis begins at $\sim 30$ years of age, and atrophy and degeneration of the SV in the cochlea are its major features (5).

The SV of the cochlear wall is the main tissue that produces the endocochlear potential (EP), which is crucial for maintaining the high-potassium state of the internal lymphatic fluid (6). The SV includes marginal cells (MCs), intermediate cells (ICs) and basal cells (BCs), all of which exert varying effects on the maintenance of internal lymph (6). The ICs, BCs and spiral ligament fiber cells of the SV are closely associated, and form a functional syncytium (7-9). The space between the syncytium layer and MCs is termed the intrastrial space (IS), which contains a large number of capillaries (10). The capillaries in the IS exhibit a number of anastomoses and are arranged in a network; the direction of these capillaries follows the cochlear lateral wall $(10,11)$. The capillaries are primarily composed of endothelial cells (ECs) and pericytes (PCs) distributed at a ratio of 2:1 (12). PCs are pleomorphic cells with multiple finger-like protrusions from the cytoplasm, which contain actin filaments, myosin and binding proteins (13). PCs possess smooth muscle cell characteristics and a degree of contractile function. The protrusions can interact with multiple ECs, and information is integrated and transmitted along the length of the vessel to bidirectionally regulate the capillary diameter (13). PCs are scattered along small blood vessels, including small arteries and veins, particularly on the surface of the smallest capillaries that have almost no smooth muscle cells attached $(13,14)$. PCs can also differentiate into other cell types; when capillaries are damaged, PCs can proliferate and differentiate into ECs and fibroblasts (15-17). Additionally, pericytes serve an important role in angiogenesis, blood flow regulation, vascular integrity and tissue fibrosis (16-19). Many diseases such as stroke, myocardial infarction, and diabetic retinopathy are associated with vascular dysfunction caused by pathological changes and deletions in pericytes (20-22). The SV is important for the functions of MCs, ICs and BCs, and the capillary network in the SV includes a large number of PCs (12); however, only a small number of studies into the IS and its internal capillary network have been previously performed, with even less research into PCs within the IS.

$\mathrm{K}^{+}$in the internal lymphatic fluid of the cochlea is the main carrier that transduces sound waves into an electrical receptor potential; however, the role of $\mathrm{K}^{+}$in the inner ear secretion and transport process is dependent on $\mathrm{Cl}^{-}$conductance. Absence of the chloride conductance gene, chloride voltage-gated channel $\mathrm{Ka}(\mathrm{ClC}-\mathrm{K})$, in the $\mathrm{SV}$ causes hearing loss in animals (23). $\mathrm{Cl}^{-}$ channels are categorized into five types in mammals: Cystic fibrosis transmembrane conductance regulators, calcium-activated chloride channels (CaCCs), voltage-gated chloride channels, ligand-gated chloride channels ( $\gamma$-aminobutyric acid and glycine-activated chloride channels) and volume-regulated chloride channels (24). CaCCs possess typical voltage dependence and $\mathrm{Ca}^{2+}$ sensitivity. Transmembrane protein 16 (TMEM16A), a CaCC, is activated by depolarization of the cell membrane and an increase in intracellular $\mathrm{Ca}^{2+}$ (25-28). TMEM16A is expressed in ECs (29), smooth muscle cells (30) and sensory cells, including dorsal root ganglion neurons $(31,32)$, olfactory cell cilia $(33)$, rods and cones $(34)$, and is important for the transmission, visual generation and amplification of olfactory signals (31-34). The function of TMEM16A has been investigated in hair cells and other supporting cell types $(35,36)$. The expression of potassium voltage-gated channel subfamily Q member 1 , solute carrier family 12 member $2, \mathrm{Na}^{+} / \mathrm{K}^{+}$-ATPase and plasma membrane calcium-transporting ATPase 2 in the cochlea has also been reported to be associated with age (37-39).

The aims of the present study were to determine whether TMEM16A was expressed in the vascular vessels of the cochlea, and whether its distribution and expression were associated with age. Guinea pig cochlear SVs were used for functional, morphological and molecular analysis of TMEM16A in the PCs of the SV, and to evaluate the association between TMEM16A and age. The objectives of the present study were to investigate the potential role for TMEM16A in the homeostasis of the cochlea, to provide a theoretical basis for preventing AHL that may lead to the development of novel clinical treatments.

\section{Materials and methods}

Experimental animals and groups. The animals were provided by the Animal Experiment Center of Xinjiang Medical University (animal use license batch no. SCXK new 2003-0001). The use of animals in the present study was approved by the Committee of Animal Experimental Ethics of The First Affiliated Hospital of Medical College, Shihezi University (permit no. A2017-168-01). Healthy auricle reflection sensitive guinea pigs $(n=50)$ were selected according to age and divided into the following groups ( $n=10 /$ group): 2 weeks group, 3 months group, 1 year group, D-galactose-induced aging model groups [D-gal group; 3-month-old guinea pigs subcutaneously injected with D-gal (300 mg/kg; $40 \mathrm{mg} / \mathrm{ml})]$ and T16Ainh-A01 group [3-month-old guinea pigs intraperitoneally injected with T16Ainh-A01 (cat. no. SML0493; Sigma-Aldrich; Merck $\mathrm{KGaA}) 50 \mu \mathrm{g} / \mathrm{kg} /$ day for 2 weeks]. T16Ainh-A01 is an inhibitor of TMEM16A. Guinea pigs with a male to female ratio of 1:1 and a body weight of 150-450 g were housed in a low-noise environment with a temperature of $18-22^{\circ} \mathrm{C}$ and a humidity of $40-70 \%$, and free access to food and water. No animals presented with otitis media, and the animal handling and experiments were performed in accordance with the Regulations of the Committee of Animal Experimental Ethics of the First Affiliated Hospital of Shihezi University Medical College.

Preparation of the senescence model. To validate the aging model, 30 healthy 3-month-old guinea pigs (male:female ratio=1:1, weight $\sim 250-350 \mathrm{~g}$ ) were randomly divided into a control group, normal saline (NS) group and senescence group (D-gal-induced aging model). Following 1 week of adaptive feeding, the control group was routinely fed without any treatment. The senescence and NS groups received subcutaneous injections (back of the neck) of D-gal $(300 \mathrm{mg} / \mathrm{kg} ; 40 \mathrm{mg} / \mathrm{ml})$ or an equivalent volume of physiological saline, respectively, twice daily. The appearance and behavior of guinea pigs 
were carefully observed. Changes in feeding, drinking water, weight, activity, hair color and glossiness were monitored. The experimental results of the Morris water maze behavior experiment and biochemical indices, malondialdehyde (MDA) and superoxide dismutase (SOD), were analyzed to determine whether the senescence model had been established successfully (40).

Morris water maze behavior analysis. An escape platform $\sim 1 \mathrm{~cm}$ below the surface of the water was placed in a circular water maze with a diameter of $1.2 \mathrm{~m}$ and a height of $0.5 \mathrm{~m}$. Each group of guinea pigs was trained twice daily for 5 days at regular intervals, with each test lasting 60 secs or until the guinea pig found the escape platform in the water. Each guinea pig was numbered and the time they found the platform every day, and each time they entered the water maze at the same location were recorded. The parameters that were monitored were escape latency (the time each guinea pig required to find the escape platform), and the number of crossings (the number of times each guinea pig swam through the place where the platform was located within $60 \mathrm{sec}$ ) when the escape platform was removed following 5 days of training (41).

Detection of biochemical indexes. Specimen collection: Guinea pigs were anesthetized with $10 \%$ chloral hydrate at a concentration of $350 \mathrm{mg} / \mathrm{kg}$, and did not detect peritonitis, pain and discomfort $(40,42,43)$. The main parameters used to monitor the depth of guinea pig analgesia included: i) Respiratory amplitude and rhythm; ii) eye movement, tearing and pupil light reflex; iii) skeletal muscle reaction (e.g. body movement and struggle); and iv) response to pinching of hind limb with hemostatic forceps. When the analgesia of the animal was sufficiently deep, the chest was opened and the blood was extracted directly from the heart. Blood was centrifuged at 5,000 x g at $4^{\circ} \mathrm{C}$ for $10 \mathrm{~min}$, and the upper serum was collected. Additionally, the liver was removed, washed with $4^{\circ} \mathrm{C}$ saline, dried and stored at $-80^{\circ} \mathrm{C}$. Subsequently, the head was removed, the parietal bone removed, and the intact brain tissue is removed and stored as described above. Finally, the cochlea was removed, and the inner ear tissue was extracted under a dissecting microscope. All the specimens were placed in a $-80^{\circ} \mathrm{C}$ freezer until subsequent use.

MDA (malondialdehyde) content detection: The MDA contents of serum, and liver, brain and inner ear tissues were detected by the thiobarbital acid (TBA) method according to the manufacturer's protocols (cat. no. A003-1-2; Nanjing Jiacheng Bioengineering Institute). The MDA content in the sample was determined as previously described (44).

SOD (superoxide dismutase) activity detection: The SOD activity in serum, and liver, brain and inner ear tissues was detected using the TBA method according to the manufacturer's protocols (cat. no. A001-3-2; Nanjing Jiacheng Bioengineering Institute). The activity of SOD in the sample was determined as previously described (44).

Auditory brainstem response $(A B R)$ detection. Guinea pigs were anesthetized by intraperitoneal injection and placed in a soundproof screening room. An acupuncture needle with a diameter of $0.38 \mathrm{~mm}$ and a length of $5 \mathrm{~cm}$ was used as the recording electrode. The recording electrode was inserted $\sim 1.0 \mathrm{~cm}$ deep into the subcutaneous periosteum at the midline of the skull and reached the midpoint between the bilateral external auditory canals. The reference electrode was placed in mastoid area of the test ear and the tip of the nose was used for the grounding electrode. Sound waves were stimulated by a short sound (click) delivered to both ears simultaneously. The scan time was $10 \mu \mathrm{sec}$, and the superimposed number was 1,024 . The stimulation protocol included stimulus intervals of $11.10 \mathrm{beats} / \mathrm{sec}$, with stimulation intensity gradually decreasing by $20 \mathrm{~dB}$ nHL. When approaching the threshold of response, the stimulation intensity was gradually reduced by $5 \mathrm{~dB}$ nHL. The experiment measured variation in the amplitude and latency of ABR I waves between the age groups in response to $90 \mathrm{~dB}$ nHL stimulation, and differences in the acoustic threshold of ABR I waves $(40,45)$.

TMEM16A immunofluorescence. Guinea pigs were anesthetized and the chest was opened. Saline was perfused through the ascending aorta to flush blood from the right atrium, and then $40 \mathrm{~g} / \mathrm{l}$ paraformaldehyde $\left(500 \mathrm{ml}, 4^{\circ} \mathrm{C}, 1 \mathrm{~h}\right)$ was used for perfusion-fixation. Following cervical dislocation, parietal bone and brain tissue were removed. The bilateral temporal bone was collected quickly, and redundant bone tissue was removed to retain the cochleas. Samples were immersed in $40 \mathrm{~g} / \mathrm{l}$ paraformaldehyde solution at $4^{\circ} \mathrm{C}$ for $48 \mathrm{~h}$. Specimens were decalcified in $100 \mathrm{~g} / 1 \mathrm{EDTA}\left(25^{\circ} \mathrm{C}\right)$ for 5 days, then moved into $250 \mathrm{~g} / \mathrm{l}$ sucrose for 4-6 h. Samples were then embedded in optimal cutting temperature compound, and continuous, parallel, $10-\mu \mathrm{m}$ frozen sections were cut and stored at $-80^{\circ} \mathrm{C}$.

For antigen retrieval, the prepared frozen sections were placed in citrate buffer solution $(0.01 \mathrm{mmol} / 1, \mathrm{pH} 6.0)$ and heated in a microwave for $3 \mathrm{~min}$. Then, sections were microwaved at low heat for $5 \mathrm{~min}$, high heat for $1 \mathrm{~min}$ and low heat again for $5 \mathrm{~min}$, and then stored at room temperature. Subsequently, sections were washed in PBS $(0.01 \mathrm{mmol} / \mathrm{l}$; 3 washes for $5 \mathrm{~min}$ each), incubated in $0.3 \%$ Triton-100 $(100 \mu \mathrm{l})$ for $30 \mathrm{~min}$ and washed again. Sections were blocked in 5\% bovine serum albumin (cat. no. B2064; Sigma-Aldrich; Merck KGaA)at room temperature for $1 \mathrm{~h}$. The blocking buffer was removed, and the sections were dried and then incubated with rabbit anti-TMEM16A antibody (1:100; cat. no. ab64085; Abcam) and mouse anti-desmin monoclonal antibody (1:100; cat. no. ab8470; Abcam) at $4^{\circ} \mathrm{C}$ overnight. The following day, the temperature was increased to $37^{\circ} \mathrm{C}$ for $45 \mathrm{~min}$, and then sections were washed. Slides were incubated with FITC-conjugated goat anti-rabbit and TRITC-conjugated goat anti-mouse secondary antibody (1:100, ZF-0311 and ZF-0313; OriGene Technologies, Inc.) at room temperature for $60 \mathrm{~min}$, and then washed. Sections were stained with 4,6-diamino-2-phenyl indole (DAPI; Solarbio Science and Technology Co.) at $37^{\circ} \mathrm{C}$ for $15 \mathrm{~min}$ and then washed. Finally, the slides were sealed with glycerol buffer, and sections were observed and quantified at a magnification of 200x using a laser scanning confocal microscope (Zeiss LSM 510 META, Carl Zeiss AG) (40).

Reverse transcription-quantitative PCR (RT-qPCR). The levels of TMEM16A mRNA in the cochlea SV were determined via RT-qPCR analysis as previously described (33). Total RNA was 

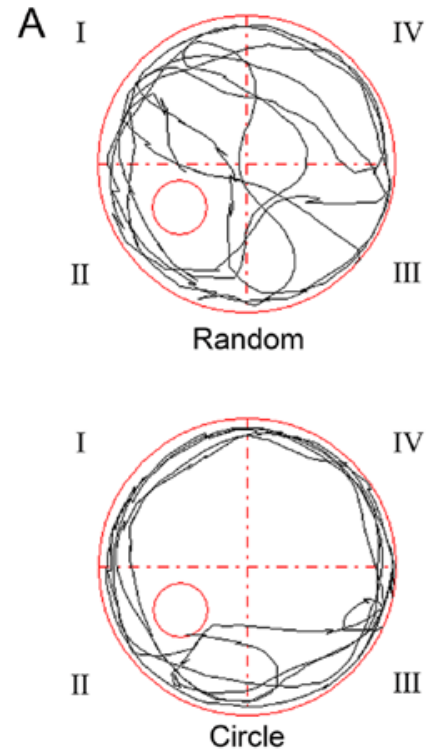

$B_{\text {I }}$
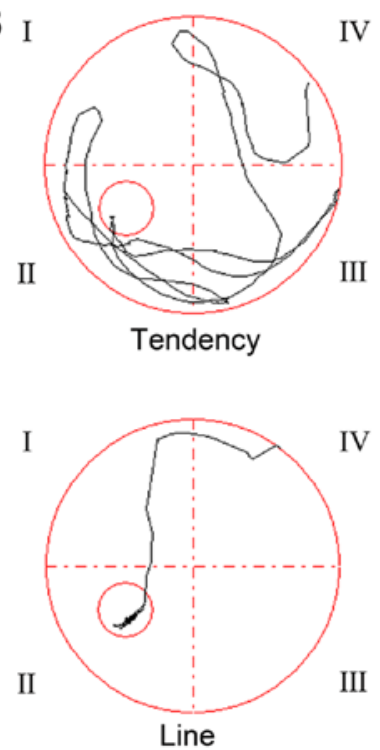

$\mathrm{C}_{\mathrm{I}}$
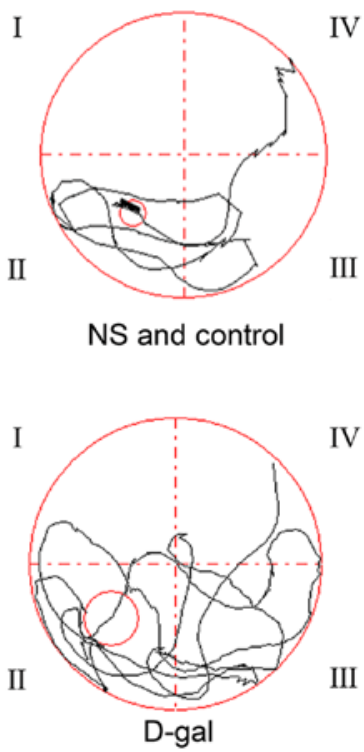

Figure 1. Trajectory of guinea pig movement in the Morris water maze. (A) In the hidden platform experiment, the guinea pigs began to search for the platform in two manners: Random searching and circular movement. (B) As the amount of training received increased, the guinea pigs began to search near the platform location with increased tendency, or swim in direct lines to the platform; however, animals in the D-gal did not exhibit similar changes in behavior. (C) In the search platform experiment, animals in the D-gal group exhibited a notably lesser preference for the former location of the platform compared with the NS and control groups. NS, normal saline; D-gal, D-galactose.

extracted using TRIzol ${ }^{\circledR}$ (Thermo FisherScientific, Inc.) according to the manufacturer's protocols. Total RNA was reverse transcribed into cDNA using SuperScript ${ }^{\mathrm{TM}}$ III reverse transcriptase and oligo primers as follows: $42^{\circ} \mathrm{C}$ for $60 \mathrm{~min}$ and $70^{\circ} \mathrm{C}$ for $5 \mathrm{~min}$ (Thermo Fisher Scientific, Inc.). The following primers were used for qPCR amplification: $\beta$-actin, forward 5'-CGTAAAGAC CTCTATGCCAACAG-3', reverse 5'-AGCCACCATCCACACA GAG-3'; and TMEM16A, forward 5'-CACTCTTCGCCCTGC TAAAC-3', and reverse 5'-ACCAGATGCCGATGTCTTTG-3'. The thermocycling conditions consisted of $3 \mathrm{~min}$ of hot-start enzyme activation at $95^{\circ} \mathrm{C}$, followed by 45 cycles of $\mathrm{PCR}$ at $95^{\circ} \mathrm{C}$ for $15 \mathrm{sec}$ (denaturation), $60^{\circ} \mathrm{C}$ for $40 \mathrm{sec}$ (annealing) and $72^{\circ} \mathrm{C}$ for $30 \mathrm{sec}$ (elongation). Amplification was confirmed by the presence of a single peak in the melting temperature analysis and linear amplification throughout the PCR cycles. The $2^{-\Delta \Delta \mathrm{Cq}}$ method (46) was used to analyze relative mRNA expression of target genes. $\beta$-actin was used as the internal control.

Western blot analysis. Cochlear blood vessels and spiral ligament tissues were collected (>10 mg). Protein lysis buffer (RIPA: PMSF 100:1; Solarbio Science and Technology Co.), was added to the samples, which were then centrifuged at $24,000 \mathrm{x} \mathrm{g}$ for $10 \mathrm{~min}$ at $4^{\circ} \mathrm{C}$. The supernatant was collected, and bicinchoninic acid protein assay kits were used to determine the protein concentration. Sample buffer was added to the lysates, and then samples were boiled to denature the protein. Each sample with equal amounts of protein ( $15 \mu \mathrm{g} /$ lane) was separated by $10 \%$ SDS-PAGE electrophoresis. Following electrophoresis, the separated protein bands were transferred to polyvinylidene difluoride membranes. Blocking was performed in 5\% milk for $2 \mathrm{~h}$ at room temperature, then TMEM16A polyclonal antibody (1:200 cat. no. ab64085; Abcam) and $\beta$-actin antibody $(1: 1,000$, sc-47778, Santa Cruz Biotechnology, Inc.) was incubated with the membranes at $4^{\circ} \mathrm{C}$ overnight. Following washing in TBS-Tween 20 (TBST, $0.2 \%$ Tween 20) buffer, horseradish peroxidase-conjugated secondary antibody [1:20,000, horseradish peroxidase-conjugated goat anti-rabbit or goat anti mouse secondary antibodies (ZB-2301 and ZB-2305; ZSGB-BIO OriGene Technologies, Inc.)] was incubated with the membranes at room temperature for $1 \mathrm{~h}$. Following further washing in TBST, ECL reagent (cat. no. RPN2109; GE Healthcare Life Sciences) was added, and proteins were detected by exposure to X-ray film. The optical density of each target protein band was assessed with Quantity One software version 4.6.6 (Bio-Rad Laboratories, Inc.) as previously described (47).

Statistical analysis. Statistical analysis was performed using SPSS 19.0 software (IBM Corp.), and GraphPad Prism 5 (GraphPad Software, Inc.) was used to generate graphs. Experimental data, ABR analysis and western blotting are expressed as the mean \pm standard deviation. Data were analyzed using one-way analysis of variance, a least significant difference post hoc test was used to compare two groups following ANOVA. $\mathrm{P}<0.05$ was considered to indicate a statistically significant difference.

\section{Results}

General characteristics of the model guinea pigs. At 4 weeks after D-gal was administered, and the aging model was successfully established, guinea pigs in the D-gal group appeared weak and exhibited reduced appetite, loose skin and hair loss. The appearance and general state of the control and NS groups were nearly identical to those prior to the experiment.

Morris water maze behavior analysis. At the beginning of the water maze experiment, the time required by the guinea pigs to identify the platform was $\sim 60 \mathrm{sec}$ (Figs. 1 and 2). In the first few days of training, two main paths, random and circular, were used by the guinea pigs to find the platform (Fig. 1A). As the 

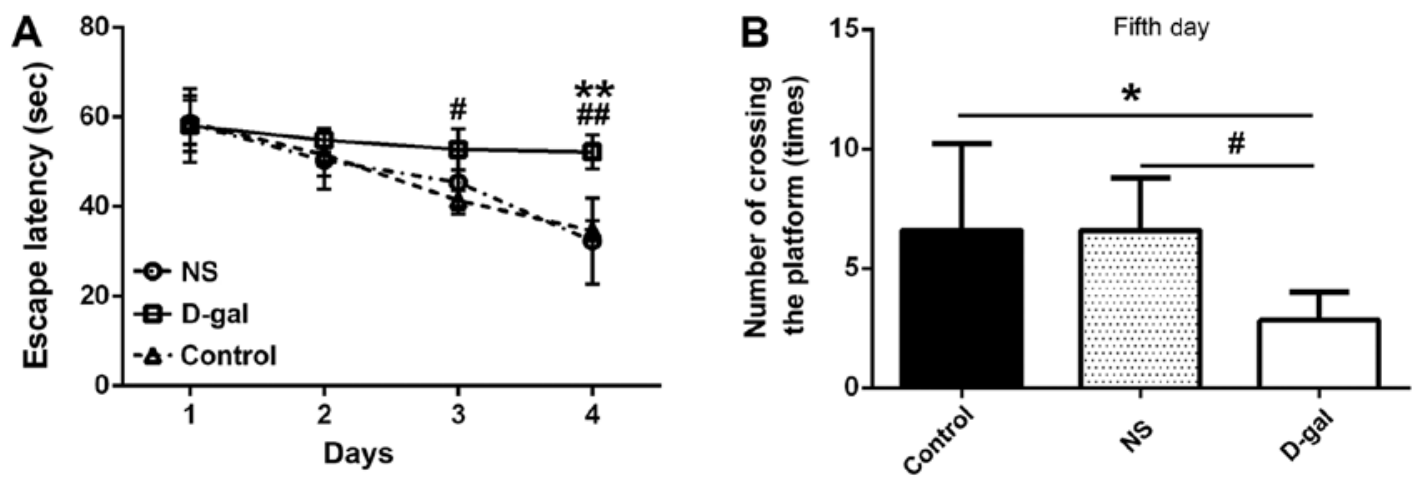

Figure 2. Effects of D-gal on the behavior of guinea pigs in the Morris water maze. (A) In the search platform, the D-gal group lagged the control and NS groups starting from the day 3. (B) Frequency of crossing the former platform location following removal of the hidden platform. Data are presented as the mean \pm standard deviation $(\mathrm{n}=10) .{ }^{*} \mathrm{P}<0.05,{ }^{* *} \mathrm{P}<0.01$ vs. control; ${ }^{*} \mathrm{P}<0.05,{ }^{\# \#} \mathrm{P}<0.01$ vs. NS. NS, normal saline; D-gal, D-galactose.
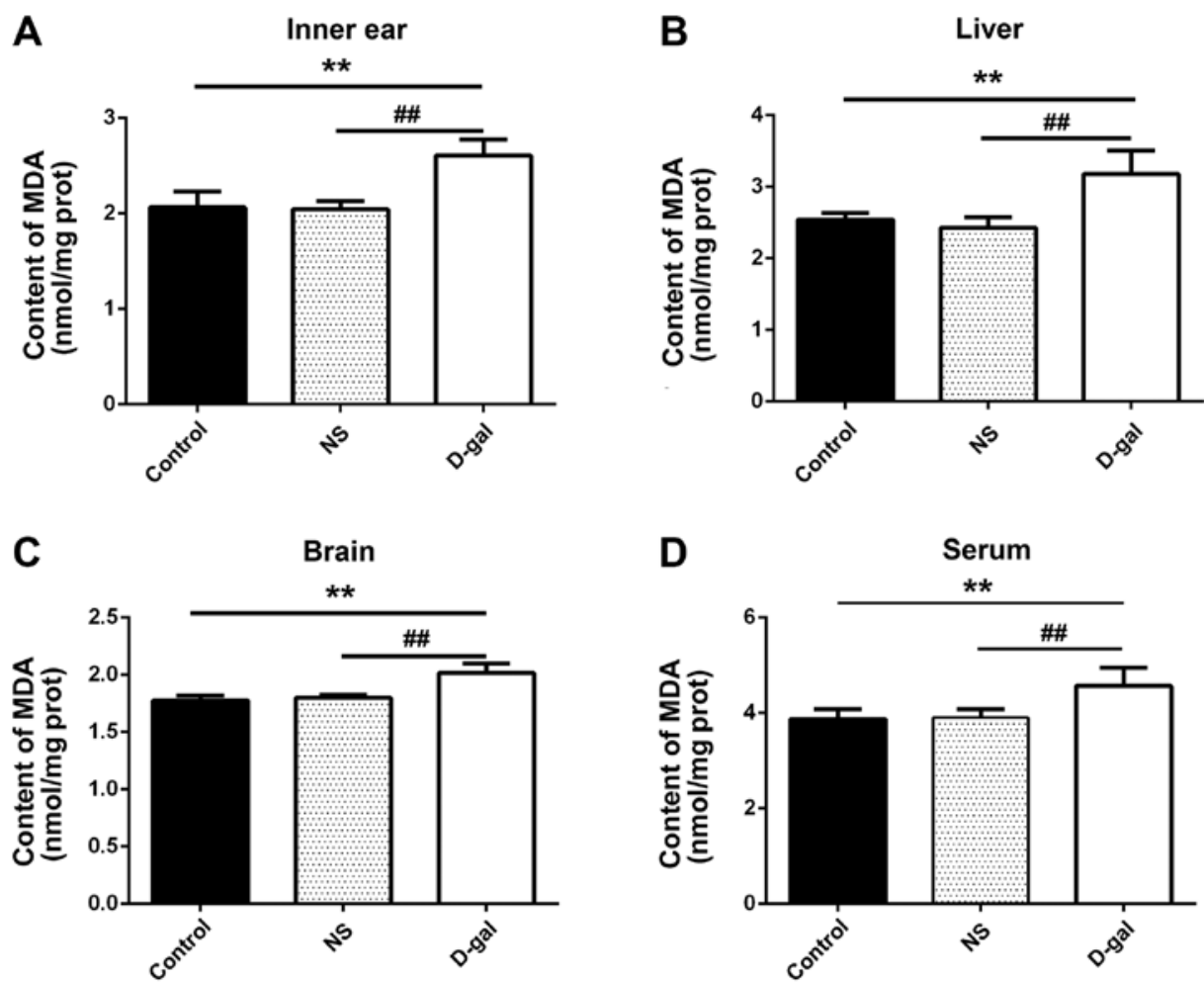

Figure 3. MDA content in the guinea pig model of aging. MDA content in (A) inner ear, (B) liver, (C) brain and (D) serum samples from control, and NS- and D-gal-treated guinea pigs. Data are presented as the mean \pm standard deviation $(n=10)$. ${ }^{* *} \mathrm{P}<0.01$ vs. control; ${ }^{\# \#} \mathrm{P}<0.01$ vs. NS. NS, normal saline; D-gal, D-galactose; MDA, malondialdehyde.

number of training events increased, the time and path to find the hidden platform changed in the control and the NS groups; the path approached a straight line (Fig. 1B); however, there were no obvious changes in the $\mathrm{D}$-gal group. Following 4 days of training, the time required for the control and NS guinea pigs to find the hidden platform was gradually reduced; however, the $\mathrm{D}$-gal group required more time to find the platform than the control and NS groups (Fig. 2A). No significant difference was observed between the three experimental groups on day 1 $[58.69 \pm 5.56,57.58 \pm 9.43$ and $58.69 \pm 6.96 \mathrm{sec}$ (control, NS and $\mathrm{D}$-gal, respectively); $\mathrm{n}=10 ; \mathrm{P}>0.05]$. On days $2-4$, the escape latency of the D-gal group was increased compared with the control and NS groups, and by day 3 , the difference between the groups was statistically significant $(\mathrm{P}<0.05 ; \mathrm{n}=10$; Fig. $2 \mathrm{~A})$.
On day 5 of the experiment, the hidden platform was removed from the water (Fig. 1C). The number of times that the D-gal group crossed the area previously containing the hidden platform $(3.17 \pm 1.33)$ was significantly reduced compared with the control and NS groups $(6.40 \pm 3.78$ and $6.60 \pm 2.19$, respectively; $\mathrm{n}=10 ; \mathrm{P}<0.05$; Fig. $2 \mathrm{~B}$ ). These results indicated that the spatial learning ability of guinea pigs in the D-gal group was impaired compared with animals in the control and NS groups.

Biochemical index detection (SOD and MDA). MDA content and SOD activity were detected in inner ear, liver and brain tissue, and serum samples from guinea pigs. The MDA content in the D-gal group was significantly increased compared with in the NS and control groups ( $n=10 ; \mathrm{P}<0.01 ;$ Fig. 3). Furthermore, 

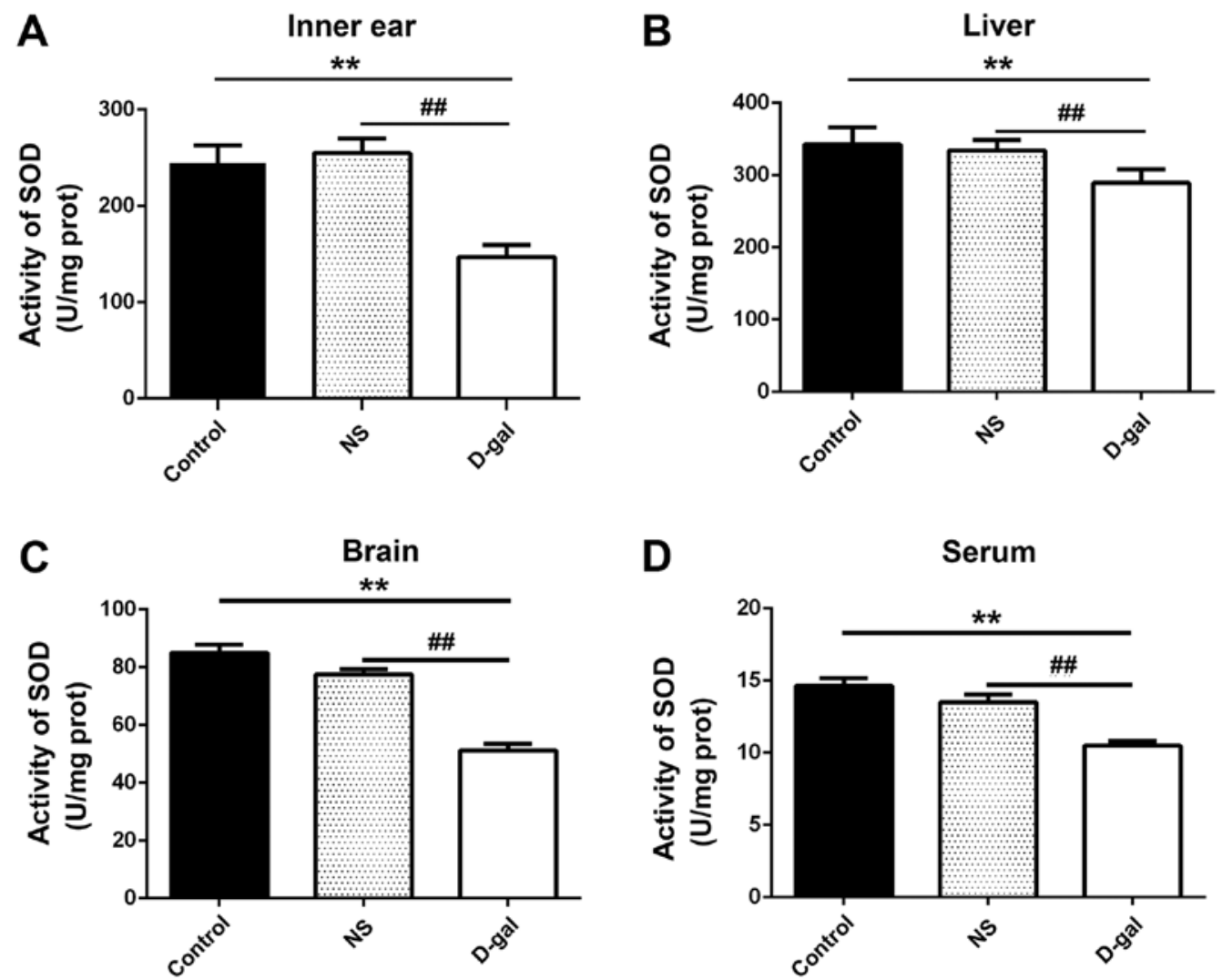

Figure 4. SOD activity in the guinea pig model of aging. SOD activity in (A) inner ear, (B) liver, (C) brain and (D) serum samples from control, and NS- and D-gal-treated guinea pigs. Data are presented as the mean \pm standard deviation $(n=10)$. ${ }^{* *} \mathrm{P}<0.01$ vs. control; ${ }^{\# \#} \mathrm{P}<0.01$ vs. NS. NS, normal saline; D-gal, D-galactose; SOD, superoxide dismutase.

SOD activity was significantly reduced in the D-gal group compared with in the NS and control groups $(\mathrm{P}<0.01$; Fig. 4). The results indicated that the $\mathrm{D}$-gal group exhibited decreased SOD activity and increased MDA content, further suggesting that the natural aging process was successfully simulated the D-gal group guinea pigs.

$A B R$ detection in guinea pigs of different ages. To explore differences in auditory ability, ARB tests were performed on the different groups of guinea pigs. After subjecting each group to 5-90 dB stimulation, different waveforms were obtained (Fig. 5A-E). As the first wave (I wave) is clear and stable, it can be used to evaluate auditory ability (45). The latency, threshold and amplitude of the I wave were recorded for further evaluation. There was no difference in the latency of I waves between the groups $(\mathrm{n}=10 ; \mathrm{P}>0.05$; Fig. 5F). The threshold of I waves in guinea pigs gradually increased with age. Compared with the 3 months $(5.8 \pm 1.8 \mathrm{~dB}$ nHL) and 1 year $(15.1 \pm 2.2 \mathrm{~dB} \mathrm{nHL})$ groups, the threshold of the D-gal group $(22.9 \pm 2.1 \mathrm{~dB} n H L)$ was significantly increased $(n=10 ; \mathrm{P}<0.01$; Fig. 5G). Additionally, the threshold of the T16Ainh-A01 group (25.8 $\pm 2.5 \mathrm{~dB} \mathrm{nHL})$ was significantly increased compared with the 3 months group $(\mathrm{n}=10 ; \mathrm{P}<0.001)$. Compared with the 3 months $(6.34 \pm 0.16 \mu \mathrm{V})$ and 1 year $(5.63 \pm 0.18 \mu \mathrm{V})$ groups, the amplitude of I waves was significantly decreased in the D-gal group $(2.58 \pm 0.20 \mu \mathrm{V} ; \mathrm{n}=10$; $\mathrm{P}<0.01$; Fig. 5H). Furthermore, compared with the 3 month and 1 year groups, the I wave amplitude was significantly decreased in the T16Ainh-A01 group $(3.78 \pm 0.21 \mu \mathrm{V} ; \mathrm{n}=10$;
$\mathrm{P}<0.001$; Fig. $5 \mathrm{H})$; however, there was no difference in the I wave amplitude between the T16Ainh-A01 and the D-gal groups.

TMEM16A expression in cochleas of different aged guinea pigs. TMEM16A immunofluorescence staining (green) revealed that TMEM16A was widely expressed in cochlear SV cells and widely distributed in the cochlea of guinea pigs in the different age groups ( 2 week, 3 months, 1 year and D-gal groups; Fig. 6A). Desmin (red), a specific marker of PCs, was used to determine the location of these cells. Semi-quantitative statistical analysis revealed that TMEM16A fluorescence intensity gradually increased with age, and that the fluorescence intensity of PCs was consistent with the fluorescence intensity of all SV cells; however, the fluorescence intensity of TMEM16A was significantly decreased in the D-gal group compared with in the 3 months and 1 year groups (Fig. 6B). Conversely, there was no difference in TMEM16A fluorescence intensity between the D-gal group and 2 weeks group (Fig. 6B).

$m R N A$ content of TMEM16A in the cochlear SV of guinea pigs of different ages. The mRNA expression of TMEM16A in SV cells in guinea pig cochleas varied between the different groups $(\mathrm{n}=6$; $\mathrm{P}<0.05$; Fig. 7). With maturation, the mRNA levels of TMEM16A also increased. The mRNA level of TMEM16A in the D-gal group was significantly reduced compared with the 3 months and 1 year groups $(\mathrm{n}=6 ; \mathrm{P}<0.05)$, and was similar to that of the guinea pigs in the 2 weeks group (Fig. 7). 
A 2 weeks

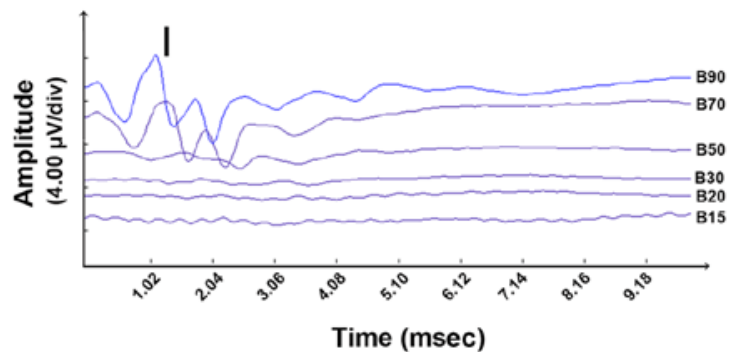

C 1 year

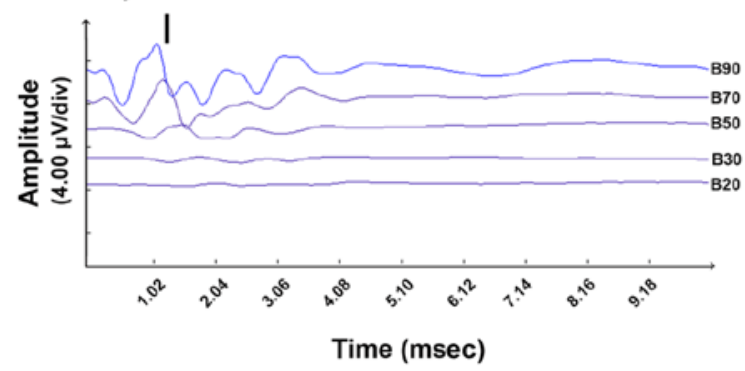

E
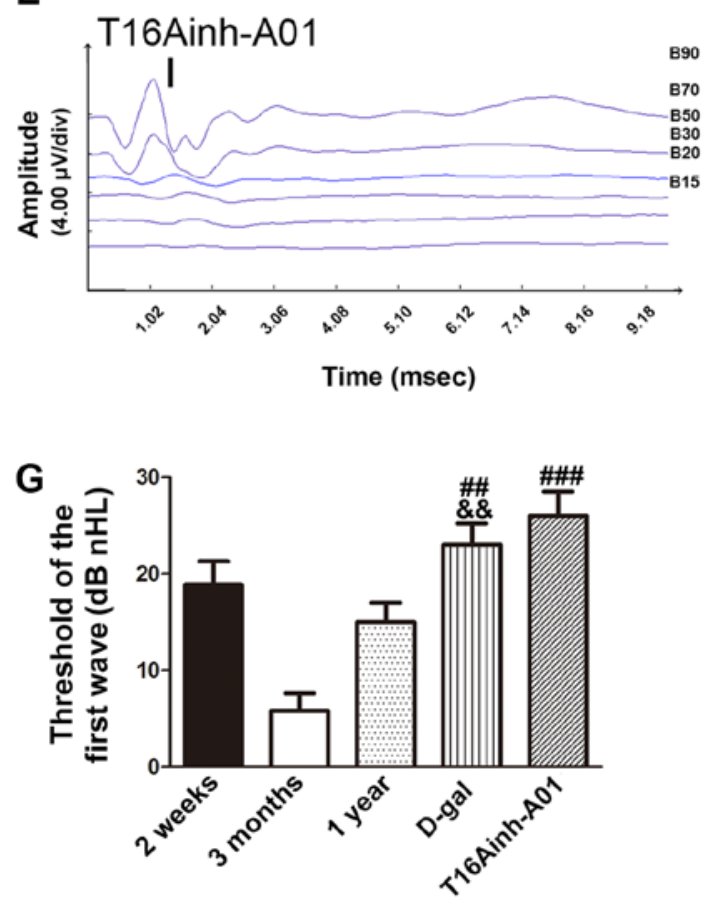

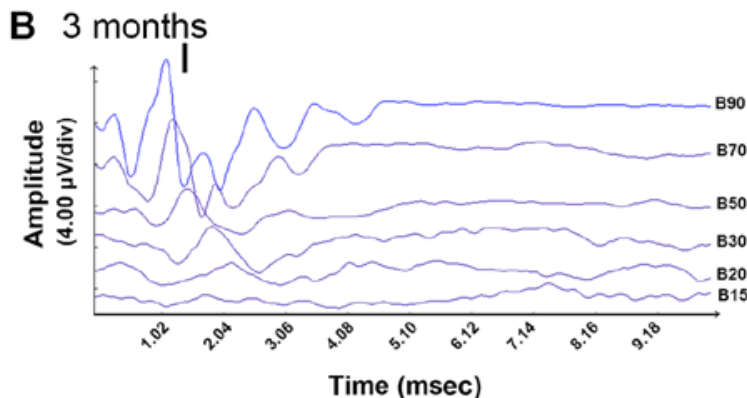

D D-gal

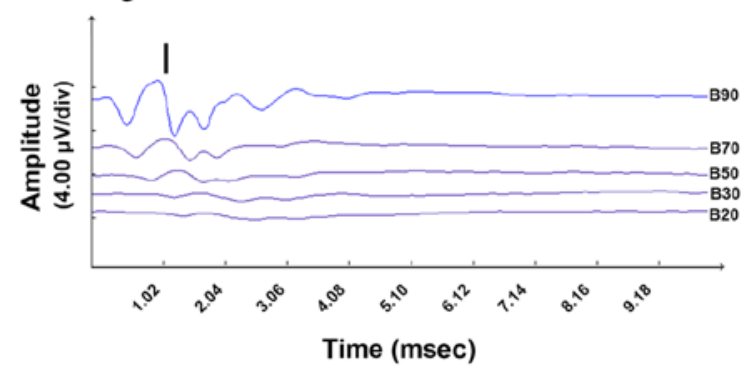

F

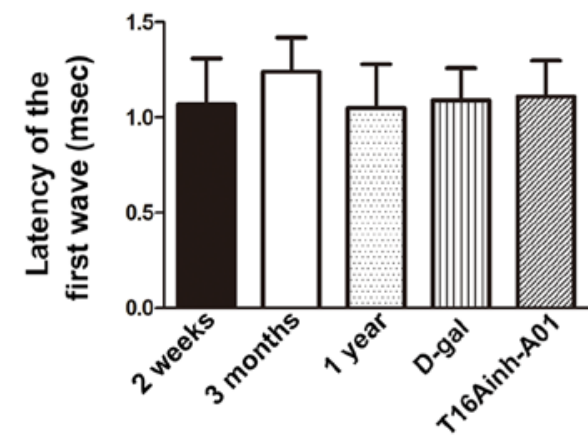

H

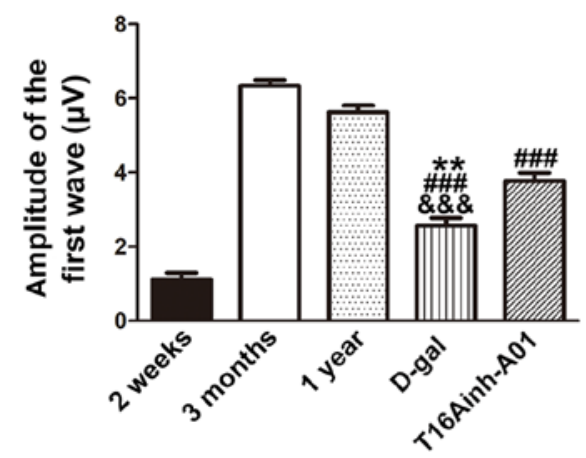

Figure 5. ABR waveform of guinea pigs in different age groups. ABR waveforms in guinea pigs from the (A) 2 weeks, (B) 3 months, (C) 1 year, (D) D-gal and (E) T16Ainh-A01 groups. (F) Latency of the first wave in each group. (G) Threshold of the first wave in each group. (H) Amplitude of the first wave in each group. Data are presented as the mean \pm standard deviation $(\mathrm{n}=10) .{ }^{* *} \mathrm{P}<0.01$ vs. 2 weeks; ${ }^{\# \#} \mathrm{P}<0.01,{ }^{\# \# \#} \mathrm{P}<0.001$ vs. 3 months; ${ }^{\&} \mathrm{P}<0.01,{ }^{\& \& \&} \mathrm{P}<0.001$ vs. 1 year. D-gal, D-galactose; ABR, auditory brainstem response; $\mathrm{dB}$ nHL, decibel above normal adult hearing level.

Changes in TMEM16A protein in SV cells. The molecular size of TMEM16A in guinea pigs was $\sim 114 \mathrm{kD}$, according to the western blot analysis. With maturation, TMEM16A protein expression was increased in SV cells. TMEM16A expression was significantly reduced in the D-gal group compared with the 3 months and 1 year groups, consistent with the immunofluorescence and the mRNA data $(n=6 ; P<0.05$; Fig. 8). Consistent with the other experimental results, the expression of TMEM16A protein in the D-gal group was decreased to a level similar to that in the 2 week group, indicating that the hearing of aged guinea pigs may be reduced to the same level as that of newborn guinea pigs.

\section{Discussion}

The present study yielded a number of meaningful results. First, ABR measurements revealed no difference in the latency of I waves between the groups. The threshold of the I wave in guinea pigs was gradually increased with age. Compared with the 3 months and 1 year groups, the I wave threshold 


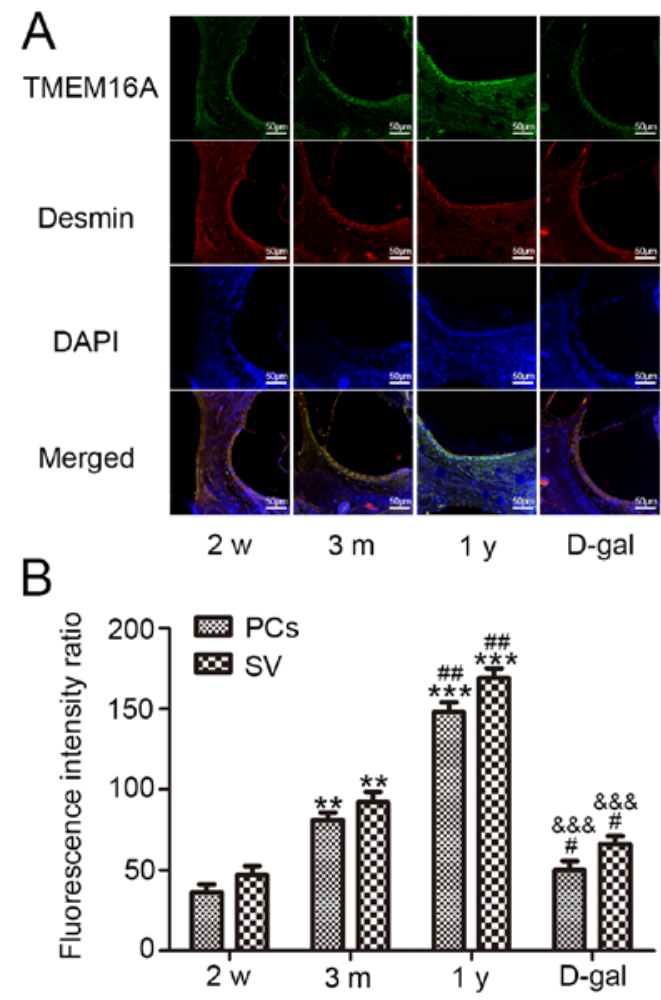

Figure 6. Distribution of TMEM16A in the PCs in the SV of guinea pigs. (A) SV was stained for TMEM16A (green) and desmin (red) as a specific marker of PCs (arrows indicate PCs in the SV). DAPI (blue) was used to stain nuclei. Scale bars $=50 \mu \mathrm{m}$. (B) Quantification of TMEM16A expression at different ages; similar fluorescence intensity was observed in PCs and the overall SV. Data are presented as the mean \pm standard deviation $(\mathrm{n}=10)$. ${ }^{* *} \mathrm{P}<0.01,{ }^{* * * *} \mathrm{P}<0.001$ vs. 2 weeks; ${ }^{*} \mathrm{P}<0.05,{ }^{\# \prime} \mathrm{P}<0.01$ vs. 3 months; ${ }^{\& \& \&} \mathrm{P}<0.001$ vs. 1 year. D-gal, D-galactose; TMEM16A, transmembrane protein 16 $\mathrm{SV}$, stria vascularis; PC, pericytes.

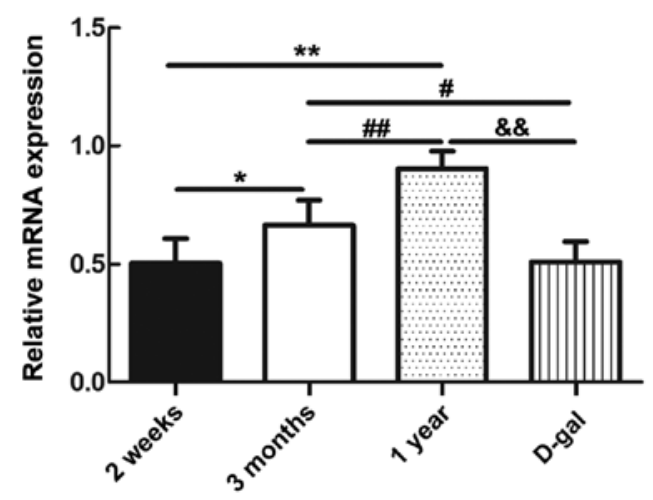

Figure 7. mRNA levels of TMEM16A in guinea pigs. TMEM16A mRNA expression expressed in stria vascularis cells in the cochleas of guinea pigs from the different age groups. Data are presented as the mean \pm standard deviation ( $\mathrm{n}=6$ ). ${ }^{*} \mathrm{P}<0.05,{ }^{* * *} \mathrm{P}<0.01$ vs. 2 weeks; ${ }^{"} \mathrm{P}<0.05,{ }^{\# \#} \mathrm{P}<0.01$ vs. 3 months; ${ }^{\&} \& \mathrm{P}<0.01$ vs. 1 year. D-gal, D-galactose; TMEM16A, transmembrane protein 16 .

of the D-gal group was significantly increased, whereas the amplitude of the I waves in the D-gal group decreased significantly. Treatment with the TMEM16A-specific blocker, T16Ainh-A01, replicated the experimental results of the D-gal group. Immunofluorescence was used to examine TMEM16A expression in the SV of guinea pig cochlea samples from the various age groups. As the age of guinea pigs increased
( 2 weeks to 1 year), the TMEM16A expression fluorescence intensity was increased; however, TMEM16A expression was decreased in the D-gal group. RT-qPCR analysis demonstrated that the mRNA levels of TMEM16A in guinea pig cochleas were highest in the 1 year age group, and that there were significant differences among the other groups. The TMEM16A mRNA levels were higher in the 3 months group than in the 2 weeks and the D-gal groups. Western blot analysis demonstrated that expression of TMEM16A protein in guinea pig cochlea samples was highest in the 1 year age group, and that significant differences were observed among the other groups. TMEM16A protein expression was higher in the 3 month group than in the 2 week and D-gal groups. The results indicated that the CaCC TMEM16A in the cochlear SV may be associated with the development of hearing in guinea pigs, and that reduced function/expression of TMEM16A may be associated with AHL.

Models of aging include the natural aging of SMAP mice (48), gamma ray irradiation (49), thymus removal and D-gal-induced aging (49). Among these models, the SMAP senescence model is the most similar to the natural aging process (48); however, this model is expensive and has not been previously used for investigating hearing. The gamma ray irradiation method is based on the theory of free radicals; gamma rays can produce a variety of free radicals in the body, including $\mathrm{O}_{2}$ and $\mathrm{OH}^{-}$, which cause damage to biological membranes (49) and promote the characteristics of rapid aging in animals (49); however, gamma rays are more commonly used to simulate aging in cell lines, rather than in animal studies $(50,51)$. In the thymus excision method, removal of the thymus can lead to the reduction or absence of cellular immune responses, which can accelerate aging; however, this is a complex animal model that is difficult to produce, and there is risk of damage to the animal during the surgery (with a high postoperative animal death rate) (49).

D-gal has been widely used to generate a guinea pig senescence model in numerous studies due to the short execution time required, simple protocol and replicability $(52,53)$. D-gal induces aging by increasing the intracellular concentration of gal; gal entry into cells produces large amounts of galactitol via a reduction reaction (53). As galactitol cannot be further metabolized in cells, it accumulates and increases the osmotic pressure in cells, leading to cell swelling and dysfunction, ultimately leading to senescence (52). D-gal metabolism can also produce a large number of free radicals via the action of gal synthase, promoting aging (52). In the present study, subcutaneous injection of guinea pigs with D-gal continuously for 28 days induced the model of aging. The SOD activity in serum, liver, brain and inner ear samples from the aging model group was significantly reduced compared with the control and NS groups; conversely, the MDA content was significantly increased in the D-gal group compared with the control and NS groups. The results indicated that damage induced by free radicals and lipid peroxidation was significantly increased in the guinea pig model of aging. Furthermore, the results of the Morris water maze behavioral test and ABR experiments demonstrated that the cognitive ability and hearing of the D-gal guinea pigs was decreased. There were no differences in MDA content, SOD activity or water maze performance between the control and NS groups, indicating that the aging model was 
A

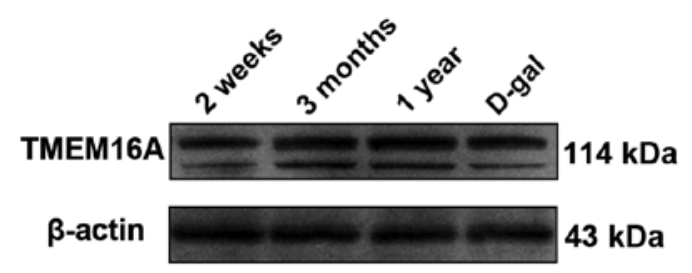

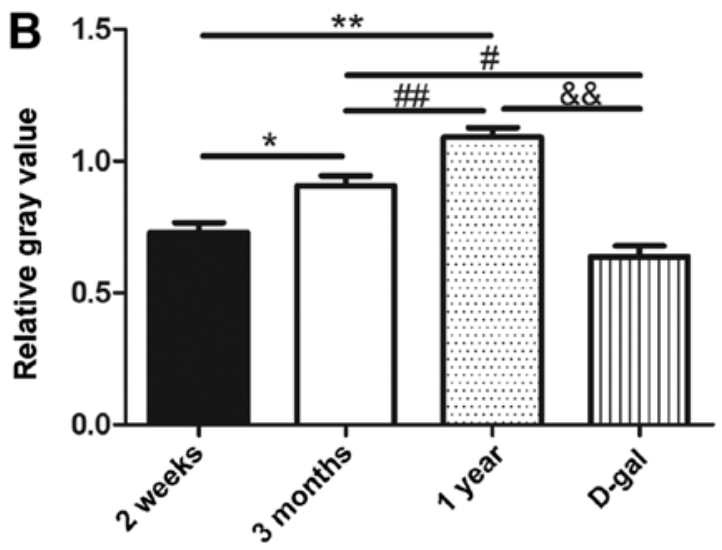

Figure 8. Protein levels of TMEM16A in guinea pigs. (A) Expression of TMEM16A in SV cells from the cochleas of guinea pigs from the different age groups, as determined via western blotting. (B) TMEM16A protein expression in SV cells varied between guinea pigs from the different age groups. Data are presented as the mean \pm standard deviation $(\mathrm{n}=6) .{ }^{*} \mathrm{P}<0.05,{ }^{* *} \mathrm{P}<0.01$ vs. 2 weeks; ${ }^{\#} \mathrm{P}<0.05,{ }^{\# \#} \mathrm{P}<0.01$ vs. 3 months; \&\& $\mathrm{P}<0.01$ vs. 1 year. D-gal, D-galactose; TMEM16A, transmembrane protein $16 ; \mathrm{SV}$, stria vascularis.

established successfully. This aging model can quickly and conveniently simulate rapid aging-associated degeneration of the cochlea and senile hearing loss in guinea pigs; it also has the advantages of short breeding cycles, low interference factors and low cost, and it also meets the requirements for physiological and pathological experimental research into senescence.

According to previous analyses of the EP and ABR, alterations in the ABR and EP are associated with changes in hearing $(54,55)$; however, EP detection is invasive and fatal, whereas ABR detection is a transient response induced by sound stimulation. Therefore, ABR is frequently used to assess hearing levels, as it exhibits good objectivity and stability (56). In CBA mice, the amplitudes of ABR I and II waves decrease with age (although the I wave is more pronounced), and the threshold increases with age (57); similar findings have been reported in the aging Fisher Brown Norway rat model, where the amplitude of ABR I waves decreases, and the threshold increases with age (46). A review of early studies reported that the latency delays of ABR I and III waves are marked when AHL occurs (58). In the present study, stable and clear ABR I waves were recorded. There were no marked differences in the ABR I wave latency between the experimental groups. From the beginning of the 3 months group, the threshold of I waves in guinea pigs gradually increased with age, but the threshold of the 2 weeks group was higher than that in the 3 months group, probably because the auditory organs were not mature. The ABR results in the study are consistent with the characteristics of AHL (59). In addition, TMEM16A-specific blockers mimicked the results observed for the D-gal group.

The SV is located in the lateral wall of the cochlea and is a metabolically active tissue (6). The $\mathrm{SV}$ secretes $\mathrm{K}^{+}$into the internal lymphatic fluid and absorbs other electrolytes, resulting in an EP (6). The main function of the SV is to maintain normal ion and bioelectric balance in the cochlea, and ensure its normal metabolism and physiological function, which is the basis of normal hearing (60). Gratton et al (61) reported that the cochlear $\mathrm{SV}$ of young gerbils exhibits a discontinuous shrinking phenomenon, and that the rate of shrinking increases with age; atrophy and the disappearance of ECs also occur. SV atrophy is a key factor that leads to AHL; when SV atrophy reaches a certain limit, the SV wall becomes thin or disappears, and the capillary vessels and PCs are decreased or lost from the SV tissue, resulting in microcirculation damage (62). Microcirculation damage leads to decreased activity of various enzymes in cells of the SV, and affects energy conversion and $\mathrm{K}^{+}$cycle transfer. These dysfunctions result in alterations in the internal environment of the cochlea and lead to a decrease in $\mathrm{K}^{+}$concentration in the lymph $(6,62)$. Consequently, the EP is reduced or lost, resulting in hearing loss or deafness (62).

The cochlear SV is composed of MCs, the IS, ICs and BCs (6). The cochlear SV forms two relatively independent barrier systems: A barrier composed of MCs, and a barrier of ICs and BCs. The area between the two barriers is the IS (7-9). $\mathrm{MCs}$, ICs and BCs serve important roles in ion transport in the cochlear SV, and the functions of these three cell types in the IS of the cochlear SV are closely connected (63-65). Abundant capillary networks are present in the IS; the capillary wall is composed of ECs, PCs, the basement membrane (BM) surrounding the vessels and perivascular macrophage cells, forming the inner ear blood labyrinth barrier (BLB) (6). The BLB maintains the solute and ion balance in the inner ear; PCs are an important component of the $\operatorname{BLB}(6,66)$. PCs are flat and protuberant cells that are distributed between ECs and the BM. The protrusions of PCs are covered with ECs, and each protrusion can associate with multiple ECs; PCs integrate and transmit information along the vessel to regulate the activity of capillaries $(67,68)$.

As the most abundant anion in the body, $\mathrm{Cl}^{-}$is crucial for maintaining the $\mathrm{K}^{+}$balance in the cochlea (23). CaCCs are widely distributed $\mathrm{Cl}^{-}$channels with important physiological functions, and TMEM16A is an important CaCC protein (25-27). Gritli-Linde et al (69) reported that TMEM16A expression is specifically enriched in the SV of mice, and expression gradually increases during the growth and development of the inner ear. Jeon et al (70) noted that TMEM16A is expressed only in the SV of the mouse cochlea and the outer hair cells of the inner olive cochlear; however, Yi et al (36) reported that TMEM16A is also expressed in the 
inner hair cells (IHCs) and inner supporting cells (ISCs). The ATP released by ISCs activates its own purinergic receptor, inducing increases in intracellular $\mathrm{Ca}^{2+}$ levels and opening of the TMEM16A channel (35). $\mathrm{Cl}^{-}$outflow through TMEM16A is accompanied by water and $\mathrm{K}^{+}$efflux, eventually inducing depolarization and contraction of IHCs, producing periodic discharges and complete electrical transduction of signals (36). Additionally, it was demonstrated that TMEM16A was expressed in the interstitial cells of Cajal (ICCs) and ISCs at 2, 6 and 10 weeks in mice, and that expression at 6 and 10 weeks was significantly increased compared with at 2 weeks; however, TMEM16A expression was lost by 16 weeks $(35,36)$. This is mostly consistent with the trend of age-associated expression of TMEM16A in vascular PCs.

The mechanism underlying this change in expression during development is yet to be fully determined. TMEM16A serves an important role in the excretion and transport of $\mathrm{Cl}^{-}$in various organs (71). During development, the accumulation of oxygen free radicals in the cochlea induces irreversible damage to cell mitochondria, resulting in a decrease in expression of the channel within the vascular groove (72); thus, $\mathrm{Cl}^{-}$is retained in $\mathrm{MCs}$, and the $\mathrm{Cl}^{-}$concentration in the IS is insufficient. This induces a compensatory increase in TMEM16A to maintain the homeostasis of the internal environment and ensure normal ion transport in the cochlea, potentially explaining the age-associated increase in TMEM16A expression. Additionally, the low expression of TMEM16A at 2 weeks following birth may be associated with the underdevelopment of the cochlea; however, by 2 years of age, severe vascular stenosis and dysfunction occurs in the mouse auditory system, with TMEM16A decompensated and its expression significantly decreased, leading to dysfunctional secretion and transport of $\mathrm{Cl}^{-}$. This results in imbalanced microcirculation homeostasis in the cochlea, eventually inducing hearing loss.

Cav1.3 is the main calcium ion channel in the inner ear; it is abundant in vascular veins in the cochlea, and its main function is to control the inward flow of $\mathrm{Ca}^{2+}(73)$. A reduction in Cav1.3 expression is closely associated with AHL (73-75). Reduced Cav1.3 expression and loss of associated functions can induce a $\mathrm{Ca}^{2+}$ imbalance in the inner ear, particularly in the cells of the cochlear vascular tissue $(74,75)$. Therefore, it was hypothesized that Cav1.3 protein expression decreases with age, resulting in decreased $\mathrm{Ca}^{2+}$ in cells and, in turn, the inability to activate CaCCs. The existing literature and the findings of the present study indicate that the muscle-like phenotypic expression of PCs (76), and electrophysiological properties that are similar to those of smooth muscle cells, regulate local capillary contraction and expansion $(77,78)$. Therefore, it was hypothesized that activation of $\mathrm{CaCCs}$ on PCs can regulate capillary vasoconstriction in the IS, thus affecting $\mathrm{K}^{+}$microcirculation, the composition of internal lymph and regulation of auditory function. Decreased TMEM16A on vascular PCs in aged guinea pigs may lead to contractile dysfunction in PCs, which may cause microcirculatory disorders in the capillary network and eventually lead to hearing impairment.

Combining the observed changes in TMEM16A and the results of the hearing analysis suggest that there is an important association between TMEM16A and senile deafness. During the mature development of guinea pig cochlea, the expression of TMEM16A increased over time, but the expression of TMEM16A decreased again during D-gal-induced aging. This process may be central in the onset and further development of senile deafness. Additionally, there was a significant loss of hearing in young guinea pigs following intervention with a TMEM16A blocker, further suggesting that the downregulation of TMEM16A is associated with hearing loss; however, the present study only revealed that TMEM16A may be associated with presbycusis to a certain extent. Its specific mechanisms of action and direct roles in the EP require further investigation in subsequent studies. Present studies involve the primary culture and identification of perivascular cells in the cochlea of guinea pigs. The effect of TMEM16A on PC function and the specific mechanisms involved should be examined using a TMEM16A gene knockout in primary cultured PCs in future studies. Nevertheless, the present findings provided a potential novel direction for the clinical prevention and treatment of AHL.

\section{Acknowledgements}

Not applicable.

\section{Funding}

The present study was supported by grants from the National Natural Science Foundation of China (grant nos. 81560175 and 81560081), the High Level Talent Research Project of Shihezi University (grant no. RCSX201705) and the project of Karamay innovative talent engineering technology (grant no. 2018RC001A-02). This research was supported by the Laboratory of Xinjiang Endemic and Ethnic Diseases.

\section{Availability of data and materials}

All data generated or analyzed during the present study are included in this published article.

\section{Authors' contributions}

JQS and LL designed the study. YZ, JS, YW and AMZ performed the experiments, performed the data analysis and wrote the manuscript. CYT, YHL, ZPZ, YW and KTM conducted the data analysis and revised the manuscript.

\section{Ethics approval and consent to participate}

The use of animals in the present study was approved by the Committee of Animal Experimental Ethics of The First Affiliated Hospital of Medical College, Shihezi University (permit no. A2017-168-01).

\section{Patient consent for publication}

Not applicable.

\section{Competing interests}

The authors declare that they have no competing interests. 


\section{References}

1. Kong Weijia: Research progress of senile deafness. Chinese Medical Abstracts: 159-160, 2010 (In Chinese).

2. Viveki RG, Halappanavar AB, Joshi AV, Pujar K and Patil S: Sociodemographic and health profile of inmates of old age homes in and around Belgaum city, Karnataka. J Indian Med Assoc 111: 682-685, 2013.

3. Vas V, Akeroyd MA, Hall DA: A Data-Driven Synthesis of Research Evidence for Domains of Hearing Loss, as Reported by Adults With Hearing Loss and Their Communication Partners. Trends Hear: 573-576, 2017.

4. Gates GA, Caspary DM, Clark W, Pillsbury HC, Brown SC and Dobie RA: Presbycusis. Otolaryngol Head Neck Surg 100, 1989.

5. Spicer SS and Schulte BA: Pathologic changes of presbycusis begin in secondary processes and spread to primary processes of strial marginal cells. Hear Res 205: 225-240, 2005.

6. Shi X: Pathophysiology of the cochlear intrastrial fluid-blood barrier (review). Hear Res 338: 52-63, 2016.

7. Kikuchi T, Kimura RS, Paul DL, Takasaka T and Adams JC: Gap junction systems in the mammalian cochlea. Brain Res Brain Res Rev 32: 163-166, 2000.

8. Forge A and Wright T: The molecular architecture of the inner ear. Br Med Bull 63: 5-24, 2002

9. Forge A, Becker D, Casalotti S, Edwards J, Marziano N and Nickel R: Connexins and gap junctions in the inner ear. Audiol Neurootol 7: 141-145, 2002.

10. Spicer SS and Schulte BA: Novel structures in marginal and intermediate cells presumably relate to functions of apical versus basal strial strata. Hear Res 200: 87-101, 2005.

11. Shi X: Physiopathology of the cochlear microcirculation. Hear Res 282: 10-24, 2011.

12. Shi X, Han W, Yamamoto H, Tang W, Lin X, Xiu R, Trune DR and Nuttall AL: The cochlear pericytes. Microcirculation 15 515-529, 2008.

13. Betsholtz C, Lindblom $\mathrm{P}$ and Gerhardt $\mathrm{H}$ : Role of pericytes in vascular morphogenesis. EXS: 115-125, 2005.

14. Thomas WE: Brain macrophages: On the role of pencytes and perivascular cells. Brain Res Brain Res Rev 31: 42-57, 1999.

15. Kurz H, Fehr J, Nitschke R and Burkhardt H: Pericytes in the mature chorioallantoic membrane capillary plexus contain desmin and alpha-smooth muscle actin: Relevance for non-sprouting angiogenesis. Histochem Cell Biol 130: 1027-1040, 2008.

16. Peppiatt CM, Howarth C, Mobbs P and Attwell D: Bidirectional control of CNS capillary diameter by pericytes. Nature 443 : 700-704, 2006.

17. Oishi K, Kamiyashiki $\mathrm{T}$ and Ito $\mathrm{Y}$ : Isometric contraction of microvascular pericytes from mouse brain parenchyma. Microvasc Res 73: 20-28, 2007.

18. Hall CN, Reynell C, Gesslein B, Hamilton NB, Mishra A, Sutherland BA, O'Farrell FM, Buchan AM, Lauritzen M and Attwell D: Capillary pericytes regulate cerebral blood flow in health and disease. Nature 508: 55-60, 2014.

19. Greenhalgh SN, Iredale JP and Henderson NC: Origins of fibrosis: Pericytes take centre stage. F1000Prime Rep 5: 37, 2013.

20. Liu S, Agalliu D, Yu C and Fisher M: The role of pericytes in blood-brain barrier function and stroke. Curr Pharm Des 18: 3653-3662, 2012

21. Greif DM and Eichmann A: Vascular biology: Brain vessels squeezed to death. Nature 508: 50-51, 2014.

22. Puro DG: Physiology and pathobiology of the pericyte-containing retinal microvasculature: New developments. Microcirculation 14: 1-10, 2007.

23. Rickheit G, Maier H, Strenzke N, Andreescu CE, De Zeeuw CI, Muenscher A, Zdebik AA and Jentsch TJ: Endocochlear potential depends on $\mathrm{Cl}$ - channels: Mechanism underlying deafness in Bartter syndrome IV. EMBO J 27: 2907-2917, 2008 .

24. Wang Li and Zhang Hailing: Progress in research on function and molecular basis of $\mathrm{Ca}^{2+}$ activated $\mathrm{Cl}^{-}$channel. Chin $\mathrm{J}$ Cell Biol: 477-484, 2012 (In Chinese).

25. Caputo A, Caci E, Ferrera L, Pedemonte N, Barsanti C, Sondo E, Pfeffer U, Ravazzolo R, Zegarra-Moran O and Galietta LJ: TMEM16A, a membrane protein associated with calcium-dependent chloride channel activity. Science 322: 590-594, 2008.

26. Schroeder BC, Cheng T, Jan YN and Jan LY: Expression cloning of TMEM16A as a calcium-activated chloride channel subunit. Cell 134: 1019-1029, 2008
27. Hartzell HC, Yu K, Xiao Q, Chien LT and Qu Z Anoctamin/TMEM16 family members are $\mathrm{Ca} 2+$-activated $\mathrm{Cl}$ channels. J Physiol 587: 2127-2139, 2009.

28. Scudieri P, Sondo E, Ferrera L and Galietta LJ: The anoctamin family: TMEM16A and TMEM16B as calcium-activated chloride channels. Exp Physiol 97: 177-183, 2012.

29. Bernstein K, Vink JY, Fu XW, Wakita H, Danielsson J, Wapner R and Gallos G: Calcium-activated chloride channels anoctamin 1 and 2 promote murine uterine smooth muscle contractility. Am J Obstet Gynecol 211: 688.e1-e10, 2014

30. Manoury B, Tamuleviciute $A$ and Tammaro P: TMEM16A/Anoctamin 1 protein mediates calcium-activated chloride currents in pulmonary arterial smooth muscle cells. J Physiol 588: 2305-2314, 2010.

31. Song J, Wang Y, Liu YH, Ma KT, Li L and Jun-Qiang S: The expression of transmembrane protein 16A in guinea pig cochlea increased with years. J Xi'an Jiaotong Univ (Medical Sciences) 38: 796-802, 2017.

32. Jin X, Shah S, Liu Y, Zhang H, Lees M, Fu Z, Lippiat JD, Beech DJ, Sivaprasadarao A, Baldwin SA, et al: Activation of the Cl- channel ANO1 by localized calcium signals in nociceptive sensory neurons requires coupling with the IP3 receptor. Sci Signal 6: ra73, 2013

33. Henkel B, Drose DR, Ackels T, Oberland S, Spehr M and Neuhaus EM: Co-expression of anoctamins in cilia of olfactory sensory neurons. Chem Senses 40: 73-87, 2015.

34. Dauner K, Möbus C, Frings S and Möhrlen F: Targeted expression of anoctamin calcium-activated chloride channels in rod photoreceptor terminals of the rodent retina. Invest Ophthalmol Vis Sci 54: 3126-3136, 2013.

35. Wang HC, Lin CC, Cheung R, Zhang-Hooks Y, Agarwal A, Ellis-Davies G, Rock J and Bergles DE: Spontaneous activity of cochlear hair cells triggered by fluid secretion mechanism in adjacent support Cells. Cell 163: 1348-1359, 2015.

36. Yi E, Lee J and Lee CJ: Developmental role of Anoctamin-1/ TMEM16A in $\mathrm{Ca}(2+)$-dependent volume change in supporting cells of the mouse cochlea. Exp Neurobiol 22: 322-329, 2013.

37. Gao Y, Tao Y, Chu H, Chen J, Chen Q, Zhou L, Liu Y, Yu Y and Cui Y: Age-related expression of plasma membrane $\mathrm{Ca}(2+)$-ATPase isoform 2 in the cochleas of C57BL/6J mice. Zhonghua Er Bi Yan Hou Tou Jing Wai Ke Za Zhi 50: 934-938, 2015 (In Chinese).

38. Chen Qiu-jian, Yang Hai-di and Dai Tian-xing: Conservation of Hearing by Simultaneous Mutation of Na,K-ATPase and NKCC1. Journal of the Association for Research in Otolaryngology: 422-434, 2007

39. Li JL, Chu HQ, Zhou LQ, Xiong H, Wang Y, Chen QG, Chen J, Li ZY, Liu Y and Cui YH: Association of age-related hearing loss with ion transporter KCNQ1 and NKCC1 in cochlea of C57BL/6J mice. Zhonghua Er Bi Yan Hou Tou Jing Wai Ke Za Zhi 46: 139-143, 2011 (In Chinese).

40. Liu YH, Zhang ZP, Wang Y, Song J, Ma KT, Si JQ and Li L: Electrophysiological properties of strial pericytes and the effect of aspirin on pericyte K+channels. Mol Med Rep 17: 2861-2868, 2018.

41. Abulfadl YS, El-Maraghy NN, Ahmed AAE, Nofal S and Badary OA: Protective effects of thymoquinone on D-galactose and aluminum chloride induced neurotoxicity in rats: Biochemical, histological and behavioral changes. Neurol Res 40: 324-333, 2018.

42. Olszewski J: Guinea pig as often object to otoneurological experimental examinations. Otolaryngol Pol 61: 838-841, 2007 (In Polish).

43. Shirpoor A, Norouzi L, Khadem-Ansari MH, Ilkhanizadeh B and Karimipour M: The protective effect of vitamin $\mathrm{E}$ on morphological and biochemical alteration induced by pre and postnatal ethanol administration in the testis of male rat offspring: A three months follow-up study. J Reprod Infertil 15: 134-141, 2014.

44. Wang Z, Lin Y, Chen W, Shang J and Wei T: Transplantation of bone marrow mesenchymal stem cell improves antioxidant capacity and immune activity of aging model rats. Xi Bao Yu Fen Zi Mian Yi Xue Za Zhi 33: 151-154, 2017 (In Chinese).

45. Cai R, Montgomery SC, Graves KA, Caspary DM and Cox BC: The FBN rat model of aging: Investigation of ABR waveforms and ribbon synapse changes. Neurobiol Aging 62: 53-63, 2018.

46. Slack JL, Bi W, Livak KJ, Beaubier N, Yu M, Clark M, Kim SH, Gallagher RE and Willman CL: Pre-clinical validation of a novel, highly sensitive assay to detect PML-RARalpha mRNA using real-time reverse-transcription polymerase chain reaction. J Mol Diagn 3: 141-149, 2001.

47. Zhang M, Gao CX, Wang YP, Ma KT, Li L, Yin JW, Dai ZG, Wang S and Si JQ: The association between the expression of PAR2 and TMEM16A and neuropathic pain. Mol Med Rep 17: 3744-3750, 2018 
48. Manabe N, Kiso M, Shimabe M, Nakai-Sugimoto N and Miyamoto H: Abnormal accumulation of corpora lutea in ovaries of the senescence accelerated mouse prone (SAMP1). Int Cong Series 1260: 179-185, 2004

49. Hongliang, Fangsheng: Three different methods for establishing mouse aging models. Chinese gerontology 30: 2607-2608, 2010 (In Chinese).

50. Zhou Yuel, Wang Yapin, Wang Jian wei, et al: Effects of sirtuin 1 in positive regulation of ginsenoside Rg1 on hematopoietic stem cell and progenitor cell senescence in vivo. Chinese Journal of Anatomy 39: 5-9, 2016 (In Chinese).

51. Ling Xin, Li Wen Li, Hai, Chun xu, et al: Oxidative damage which caused by $\gamma$-rays promotes aging $\gamma$. Carcinogenesis Distortion Mutation 22: 335-338, 2010.

52. Zhu YZ and Zhu HG: Establishment and measurement of D-galactose induced aging model. Fudan Univ J Med Sci 34 617-619, 2007.

53. Wang Q, Zou L, Liu W, Hao W, Tashiro S, Onodera S and Ikejima T: Inhibiting NF- $\kappa \mathrm{B}$ activation and ROS production are involved in the mechanism of silibinin's protection against D-galactose-induced senescence. Pharmacol Biochem Behav 98: 140-149, 2011.

54. Ni C, Zhang D, Beyer LA, Halsey KE, Fukui H, Raphael Y, Dolan DF and Hornyak TJ: Hearing dysfunction in heterozygous Mitf(Mi-wh)/+ mice, a model for Waardenburg syndrome type 2 and Tietz syndrome. Pigment Cell Melanoma Res 26: 78-87, 2013.

55. Tan WJT, Song L, Graham M, Schettino A, Navaratnam D, Yarbrough WG, Santos-Sacchi J and Ivanova AV: Novel role of the mitochondrial protein Fus1 in protection from premature hearing loss via regulation of oxidative stress and nutrient and energy sensing pathways in the inner ear. Antioxid Redox Signal 27: 489-509, 2017.

56. Nuttall HE, Moore DR, Barry JG, et al. The influence of cochlear spectral processing on the timing and amplitude of the speech-evoked auditory brain stem response[J]. Journal of Neurophysiology, 2015, 113(10):3683-3691 . 2015.

57. Muniak MA, Ayeni FE and Ryugo DK: Hidden hearing loss and endbulbs of Held: Evidence for central pathology before detection of ABR threshold increases. Hear Res 364: 104-117, 2018.

58. Konrad-Martin D, Dille MF, McMillan G, Griest S, McDermott D, Fausti SA and Austin DF: Age-related changes in the auditory brainstem response. J Am Acad Audiol 23: 18-35, 2012.

59. Alvarado JC, Fuentes-Santamaría V, Gabaldón-Ull MC and Juiz JM1: Age-Related Hearing Loss Is Accelerated by Repeated Short-Duration Loud Sound Stimulation Front Neurosci 12: 28-29, 2019.

60. Hibino H, Nin F, Tsuzuki C and Kurachi Y: How is the highly positive endocochlear potential formed? The specific architecture of the stria vascularis and the roles of the ion-transport apparatus. Pflugers Arch 459: 521-533, 2010

61. Gratton MA and Schulte BA: Alterations in microvasculature are associated with atrophy of the stria vascularis in quiet-aged gerbils. Hear Res 82: 44-52, 1995.

62. Ocho S, Iwasaki S, Umemura K and Hoshino T: A new model for investigating hair cell degeneration in the guinea pig following damage of the stria vascularis using a photochemical reaction. Eur Arch Otorhinolaryngol 257: 182-187, 2000.

63. Wangemann P: Comparison of ion transport mechanisms between vestibular dark cells and strial marginal cells. Hear Res 90: 149-157, 1995.
64. Wangemann P: K+ cycling and the endocochlear potential. Hear Res 165: 1-9. 2002.

65. Takeuchi $\mathrm{S}$ and Ando $\mathrm{M}$ : Inwardly rectifying $\mathrm{K}+$ currents in intermediate cells in the cochlea of gerbils: A possible contribution to the endocochlear potential. Neurosci Lett 247: 175-178, 1998.

66. Wu Jun and Han weiju: Structural changes in thestrial bloodlabyrinth barrier of aged C57BL/6 mice. Cell Tissue Res. 685-696, 2015.

67. Bergers $\mathrm{G}$ and Song S: The role of pericytes in blood-vessel formation and maintenance. Neuro Oncol 7: 452-464, 2005.

68. Díaz-Flores L, Gutiérrez R, Varela H, Rancel N and Valladares F: Microvascular pericytes: A review of their morphological and functional characteristics. Histol Histopathol 6: 269-286, 1991.

69. Gritli-Linde A, Vaziri Sani F, Rock JR, Hallberg K, Iribarne D, Harfe BD and Linde A: Expression patterns of the Tmem16 gene family during cephalic development in the mouse. Gene Expr Patterns 9: 178-191, 2009.

70. Jeon JH, Park JW, Lee JW, Jeong SW, Yeo SW and Kim IB: Expression and immunohistochemical localization of TMEM16A/anoctamin 1, a calcium-activated chloride channel in the mouse cochlea. Cell Tissue Res 345: 223-230, 2011.

71. Oh U and Jung J: Cellular functions of TMEM16/anoctamin. Pflugers Arch 468: 443-453, 2016.

72. Groebe K, Klemm-Manns M, Schwall GP, Hübenthal H, Unterluggauer H, Jansen-Dürr P, Tanguay RM, Morrow G and Schrattenholz A: Age-dependent prosttranslational modifications of voltage-dependent anion channel 1. Exp Gerontol 45: 632-637, 2010.

73. Chen J, Chu H, Xiong H, Chen Q, Zhou L, Bing D, Liu Y, Gao Y, Wang S, Huang X and Cui Y: Expression patterns of $\mathrm{Ca}(\mathrm{V}) 1.3$ channels in the rat cochlea. Acta Biochim Biophys Sin (Shanghai) 44: 513-518, 2012.

74. Chen J, Chu H, Xiong H, Yu Y, Huang X, Zhou L, Chen Q, Bing D, Liu Y, Wang S and Cui Y: Downregulation of Cav1.3 calcium channel expression in the cochlea is associated with age-related hearing loss in C57BL/6J mice. Neuroreport 24: 313-317, 2013.

75. Inui T, Mori Y, Watanabe M, Takamaki A, Yamaji J, Sohma Y, Yoshida R, Takenaka H and Kubota T: Physiological role of L-type $\mathrm{Ca} 2+$ channels in marginal cells in the stria vascularis of guinea pigs. J Physiol Sci 57: 287-298, 2007.

76. Crisan M, Yap S, Casteilla L, Chen CW, Corselli M, Park TS, Andriolo G, Sun B, Zheng B, Zhang L, et al: A perivascular origin for mesenchymal stem cells in multiple human organs. Cell Stem Cell 3: 301-313, 2008.

77. Ma KT, Li XZ, Li L, Zhang ZP, Zhao L, Zhu H and Si JQ: Comparison of electrophysiological properties of vascular smooth muscle cells in different arterioles in guinea pig. Sheng Li Xue Bao 62: 421-426, 2010 (In Chinese).

78. Liu YH, Wang YP, Wang Y, Ma KT, Si JQ and Li L: Study on the electrophsiological properties in the stria vascularis pericytes in cochlear of guinea pig. Zhonghua Er Bi Yan Hou Tou Jing Wai Ke Za Zhi 51: 600-605, 2016 (In Chinese).

This work is licensed under a Creative Commons Attribution-NonCommercial-NoDerivatives 4.0 International (CC BY-NC-ND 4.0) License. 